\title{
Impact of Vibroacoustic Climate on Driver's Postural Stability for Eyes Closed in Driver's Cabin
}

\author{
Z. DAMiJAN ${ }^{a, *}$, S. SKRZYNIARZ $^{b}$ AND J. KWAŚNIEWSKI $^{b}$ \\ ${ }^{a}$ Department of Mechanics and Vibroacoustics, Faculty of Mechanical Engineering and Robotics \\ AGH University of Science and Technology, al. A. Mickiewicza 30, 30-059 Kraków, Poland \\ ${ }^{b}$ Department of Process Control, Faculty of Mechanical Engineering and Robotics \\ AGH University of Science and Technology, al. A. Mickiewicza 30, 30-059 Kraków, Poland
}

\begin{abstract}
Several levels of the nervous system are responsible for stability of the vertical position in humans. Three basic inputs are involved: atrial, visual and proprioceptive as well as mechanoreceptors present in the skin. Signals from these inputs control the body posture and its orientation with respect to internal and external reference systems. External systems are formed based on the gravitation field and visual stimuli. Internal systems are generated in the central nervous system by polymodal representations, also referred to as body schema. Some of environmental factors of driver's work place could disturb postural stability. Almost all vehicles are according with actual norms and directives. We investigate how normal week of work has impact on postural stability in new city buses. We concentrate on postural stability for closed eyes. In this paper results of investigation were presented.
\end{abstract}

PACS: 89.40.-a, 07.10.-h, 46.32.+x, 87.50.Y-

\section{Introduction}

The balance condition is understood as vertical orientation of the body, which can be achieved by balancing of forces and moments of force acting upon the body and the bone system interacts with the muscular system (including the postural muscles).

Stability is broadly understood as the ability of an organism to regain the correct stance after a destabilising stimulus has been applied. Sensitivity to the magnitude of the stimuli is referred to as functional stability whereas the structural stability involves also the conditions that accompany the stimulants, for instant limitation of vision.

Several levels of the nervous system are responsible for stability of the vertical position in humans. Three basic inputs are involved: atrial, visual and proprioceptive as well as mechanoreceptors present in the skin. Signals from these inputs control the body posture and its orientation with respect to internal and external reference systems. External systems are formed based on the gravitation field and visual stimuli. Internal systems are generated in the central nervous system by polymodal representations, also referred to as body schema [1-6].

The typical upright position implicates the vertical arrangement of the body axis with respect to a small supporting surface. This orientation in the gravitation field and multi-segment body structure, its height and small surface of support cause instability of the standing body in static conditions. Ongoing regulation and adjustment through the balance control system in the human body ensures its stability. Balance control involves static and

* corresponding author; e-mail: damijan@agh.edu.pl dynamic balancing of destabilising gravity and inertia forces (and their moments) and activation of appropriate groups of muscles $[1,7,8]$.

As people get older, the anatomy, biochemistry and physiology of the human body are beginning to change and these changes might negatively impact on body functions, sensitivity of the nervous systems tends to decrease while the inertia increases. The vision range and precision, eye accommodation ability and depth vision are impaired and the ability to distinguish colours is hindered, too. As one gets older, psychical and physiological functions tend to deteriorate [8-10].

\section{Methods and procedure}

Participants were selected from the group of bus drivers from the Municipal Transport Company in Tychy. Tests were continued from 24 to 31 March 2008. All participants were assumed to be healthy. The eligibility criterion in the selection of participants was the medical condition of candidates, who were qualified for the program by the doctor. Having learnt about the experimental procedure, each bus driver gave his written consent to participate. The group of participants consisted of 14 bus drivers, all males, aged 24-49. The anthropometric data are summarised in Table I.

Postural balance tests were performed with the use of the Win-pod platform (Figs. 1 and 2) manufactured by Medicapteurs Co. (France). The platform was connected to the PC via a USB port. The platform operation (program version 3.1), enabling real-time analyses, was implemented in Windows. The platform consists of a board $\left(40 \times 40 \mathrm{~cm}^{2}\right)$ with mounted tensometric sensors to register the pressure forces and moments of force exerted by 


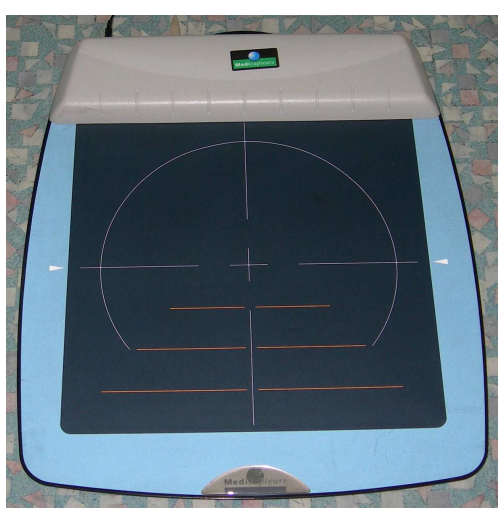

Fig. 1. Win-pod platform.

the patient's feet on the board. Sensors register displacements of the patient's centre of gravity (COG) in the plane determined by the platform. Displacement signals, converted into digital form, are recorded in the computer system and displayed in real time. The computer is used to derive the centre of pressure (COP) of the patient's feet which is interpreted as the projection of COG onto the support plane in static conditions. Obtaining graphs of COP deflections is referred to as statokinesiography, posturography or stabilography.

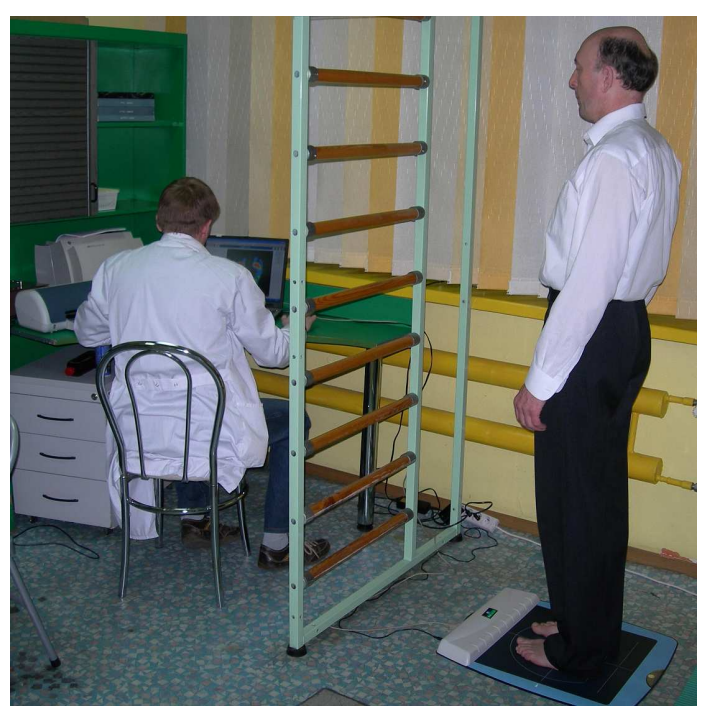

Fig. 2. Experimental setup.

Anthropometric data for the test sample.

TABLE I

\begin{tabular}{l|c|c|c|c|c|c|c|c}
\hline \hline \multicolumn{1}{c|}{ Variable } & Mean & $\begin{array}{c}\text { Confidence } \\
-95 \%\end{array}$ & $\begin{array}{c}\text { Confidence } \\
+95 \%\end{array}$ & Median & Min. & Max. & $\begin{array}{c}\text { Standard } \\
\text { deviation }\end{array}$ & $\begin{array}{c}\text { Standard } \\
\text { error }\end{array}$ \\
\hline height $[\mathrm{cm}]$ & 174.93 & 172.38 & 177.48 & 175.00 & 169.00 & 186.00 & 4.41 & 1.18 \\
body mass $[\mathrm{kg}]$ & 85.32 & 77.99 & 92.65 & 82.68 & 64.77 & 109.43 & 12.69 & 3.39 \\
age [years] & 41.64 & 37.88 & 45.41 & 42.50 & 24.00 & 49.00 & 6.52 & 1.74
\end{tabular}

Stability tests were performed in the upright position for eyes closed.

Each measurement lasted about $60 \mathrm{~s}$. Before each test, the procedure was explained to the participants to make it wholly understandable. The participant would step on the platform with bare feet. When commanded by the test supervisor, the participant would step on the platform, assume the upright position and remain immobile, standing freely for 30 s. 17 decision variables and their definitions are compiled in Table II.

For clarity, the test situations are designed as follows:

1. test before work - eyes close "Variable CB",

2. test after work - eyes close "Variable CA".

where "C" - denotes the test situation - eyes close, "B" - initial measurement, taken before work and " $\mathrm{A}$ " final measurement, taken after work.
Primary data are treated statistically by numerical methods in accordance with the statistical inference algorithm. Analysed parameters include the primary data scatter, to eliminate measurement errors and errors involved in writing the problem in the matrix format.

Having eliminated the errors in the result matrix, the descriptive statistics were obtained for all variables (mean value, median, maximum, minimum, standard error, confidence $-95 \%, 95 \%$ ). The Lilieforse and ShapiroWilk tests were applied to test the normality of distributions. In accordance with the approved confidence test selection algorithm, the difference between the confidence levels for normally distributed dependent variables was evaluated using the $\mathrm{T}$ test (designated as *), whereas the nonparametric Wilcoxon test was used (**) to handle variables that do not display normal distribution (Table III; "i" — increase, "d" — decrease). Underlined $p$-values are statistically significant. 
Dependent variables and their definitions.

TABLE II

\begin{tabular}{l|l}
\hline \hline \multicolumn{1}{c|}{ Dependent variable } & \multicolumn{1}{c}{ Definition } \\
\hline area $\left[\mathrm{mm}^{2}\right]$ & $\begin{array}{l}\text { area of feet impressions expressed as the sum of the areas of activated sensors, } \\
\text { rounded off to account for interpolation in the case of sensors located on the } \\
\text { boundary of feet impressions }\end{array}$ \\
\hline maximal pressure $[\mathrm{kPa}]$ & the highest pressure registered by a single sensor \\
\hline average pressure $[\mathrm{kPa}]$ & average pressure computed for the sum of activated sensors \\
\hline path length $[\mathrm{mm}]$ & $\begin{array}{l}\text { length of curve determined by shifting the COG projection during the postural } \\
\text { balance measurements }\end{array}$ \\
\hline velocity $[\mathrm{mm} / \mathrm{s}]$ & $\begin{array}{l}\text { the ratio of path length (see above) to the time of measurement - the average } \\
\text { ratio of deflections from the } X \text { or } Y \text { axis) }\end{array}$ \\
\hline length to area ratio $[1 / \mathrm{mm}]$ & $\begin{array}{l}\text { ratio of path length to the area of an ellipse bounded on an oscillogram de- } \\
\text { termined on the axes showing maximal sway in the } X \text {-plane (side-to-side) and } \\
Y \text {-plane (front-back) }\end{array}$ \\
\hline $\begin{array}{l}\text { RMS velocity }[\mathrm{mm} / \mathrm{s}] \\
\text { root mean square velocity }\end{array}$ & $\begin{array}{l}\text { Geometric sum of the rates of deflections from the } X \text {-axis (side-to-side) and } \\
Y \text {-axis (front-back) }\end{array}$ \\
\hline average deflection $Y[\mathrm{~mm}]$ & averaged sum of sways in the $Y$-axis (front-back) \\
\hline average sway rate $Y[\mathrm{~mm} / \mathrm{s}]$ & averaged sum of quotients of front-back sways $(Y$-axis) and the sway times \\
\hline average deflection $X[\mathrm{~mm}]$ & averaged sum of sways in the $X$-axis (side-to-side). \\
\hline average sway rate $X[\mathrm{~mm} / \mathrm{s}]$ & averaged sum of quotients of side-to-side sways $(X$-axis) and the sway times
\end{tabular}

Descriptive statistics and test of significance of differences (description in text).

TABLE III

\begin{tabular}{|c|c|c|c|c|c|c|c|c|}
\hline Variable & Mean value & $\begin{array}{c}\text { Confidence } \\
-95 \%\end{array}$ & $\begin{array}{c}\text { Confidence } \\
+95 \%\end{array}$ & Min. & Max. & $\begin{array}{l}\text { Standard } \\
\text { error }\end{array}$ & $\begin{array}{l}P \text { for } \\
\text { tests }\end{array}$ & $\begin{array}{c}\text { Fraction } \\
\text { of change } \\
{[\%]}\end{array}$ \\
\hline length $\mathrm{CB}[\mathrm{mm}]$ & 308.76 & 257.90 & 359.62 & 144.55 & 522.70 & 23.54 & $\underline{0.039}{ }^{*}$ & $\mathrm{i}-78.6$ \\
\hline length CA $[\mathrm{mm}]$ & 339.60 & 286.15 & 393.05 & 170.80 & 511.02 & 24.74 & & \\
\hline area $\mathrm{CB}\left[\mathrm{mm}^{2}\right]$ & 151.36 & 124.33 & 178.38 & 48.67 & 246.00 & 12.51 & $0.084^{* *}$ & $\mathrm{i}-78.6$ \\
\hline area $\mathrm{CA}\left[\mathrm{mm}^{2}\right]$ & 161.37 & 134.90 & 187.84 & 66.00 & 245.80 & 12.25 & & \\
\hline length/area CA $[1 / \mathrm{mm}]$ & 2.12 & 1.86 & 2.38 & 1.21 & 2.97 & 0.12 & $0.52^{*}$ & - \\
\hline length/area CB [1/mm] & 2.19 & 1.87 & 2.52 & 1.17 & 3.48 & 0.15 & & \\
\hline average velocity $\mathrm{Q} C B[\mathrm{~mm} / \mathrm{s}]$ & 9.48 & 7.95 & 11.00 & 4.47 & 15.87 & 0.71 & $\underline{0.036^{*}}$ & $\mathrm{i}-85.7$ \\
\hline average velocity $\mathrm{Q} \mathrm{CA}[\mathrm{mm} / \mathrm{s}]$ & 10.40 & 8.83 & 11.96 & 5.23 & 15.30 & 0.72 & & \\
\hline velocity $X \mathrm{CB}[\mathrm{mm} / \mathrm{s}]$ & 5.32 & 4.13 & 6.50 & 2.42 & 10.33 & 0.55 & $0.07 *$ & $\mathrm{i}-85.7$ \\
\hline velocity $X \mathrm{CA}[\mathrm{mm} / \mathrm{s}]$ & 5.85 & 4.53 & 7.17 & 2.70 & 9.93 & 0.61 & & \\
\hline velocity $Y \mathrm{CB}[\mathrm{mm} / \mathrm{s}]$ & 7.73 & 6.61 & 8.85 & 3.72 & 11.98 & 0.52 & $\underline{0.034^{*}}$ & $\mathrm{i}-78.6$ \\
\hline velocity $Y \mathrm{CA}[\mathrm{mm} / \mathrm{s}]$ & 8.45 & 7.33 & 9.58 & 4.43 & 11.53 & 0.52 & & \\
\hline$X$ average $\mathrm{CB}[\mathrm{mm}]$ & 2.66 & 2.27 & 3.06 & 1.53 & 4.00 & 0.18 & $0.22 *$ & $\mathrm{i}-64.3$ \\
\hline$X$ average $\mathrm{CA}[\mathrm{mm}]$ & 2.78 & 2.42 & 3.15 & 1.60 & 4.05 & 0.17 & & \\
\hline$Y$ average $\mathrm{CB}[\mathrm{mm}]$ & 4.26 & 3.69 & 4.82 & 2.53 & 5.78 & 0.26 & $0.75^{*}$ & $\mathrm{i}-57.1$ \\
\hline$Y$ average $\mathrm{CA}[\mathrm{mm}]$ & 4.20 & 3.80 & 4.61 & 2.97 & 5.48 & 0.19 & & \\
\hline width bb CB [mm] & 13.88 & 11.72 & 16.04 & 7.55 & 21.60 & 1.00 & $0.67^{*}$ & $\mathrm{i}-57.1$ \\
\hline width bb CA [mm] & 14.09 & 12.13 & 16.05 & 7.53 & 18.78 & 0.91 & & \\
\hline average deflection bb $\mathrm{CB}[\mathrm{mm}]$ & 2.66 & 2.27 & 3.06 & 1.53 & 4.00 & 0.18 & $0.22^{*}$ & $\mathrm{i}-64.3$ \\
\hline average deflection bb CA $[\mathrm{mm}]$ & 2.78 & 2.42 & 3.15 & 1.60 & 4.05 & 0.17 & & \\
\hline width pt $\mathrm{CB}[\mathrm{mm}]$ & 21.21 & 18.94 & 23.47 & 11.77 & 26.17 & 1.05 & $0.76^{*}$ & $\mathrm{~d}-57.1$ \\
\hline width pt $\mathrm{CA}[\mathrm{cm}]$ & 21.43 & 19.73 & 23.13 & 14.72 & 26.10 & 0.79 & & \\
\hline average deflection pt $\mathrm{CB}[\mathrm{mm}]$ & 4.28 & 3.69 & 4.87 & 2.53 & 5.88 & 0.27 & $0.66^{*}$ & $\mathrm{~d}-100.0$ \\
\hline average deflection pt CA $[\mathrm{mm}]$ & 4.20 & 3.80 & 4.61 & 2.97 & 5.47 & 0.19 & & \\
\hline
\end{tabular}

\section{Results}

In Table III results from measurements of driver's postural stability for eyes closed were showed.

\section{Conclusions}

Experimental data supported by statistical analyses reveal that the working conditions of bus drivers lead to statistically significant increase in the value of several 
posturographic parameters:

- length [mm] from 308.76 to $339.60 ; 78.6 \%$ of the sample displaying increase,

- average velocity $Q[\mathrm{~mm} / \mathrm{s}]$ from 9.48 to 10.40 ; $85.8 \%$ of the sample displaying increase,

- velocity $Y[\mathrm{~mm} / \mathrm{s}]$ from 7.73 to $8.45 ; 78.6 \%$ of the sample displaying increase.

Results of investigation show distinct growth of sway - $10 \%$ for length, $9.7 \%$ for average velocity $Q$ and $9.3 \%$ of velocity $Y$. We could infer from these results that normal week of bus driver's work could be a cause of an accident after leave of vehicle like slip on slippery surface or fall down. It could be a cause of period of transition or prolonged disability to work, which numerous investigations in USA confirm [8]. In most cases problem of balance applies to lorry drivers but our investigations proved that the problem is present in bus drivers. We suppose that drivers should do some gymnastic exercises after getting out of vehicle so that it could help recover balance and decrease risk of bodily harm in way from vehicle.

\section{Acknowledgments}

The research has been conducted within the framework of the author's research no 10.10.130.631 and the statuary ones no. 11.11.130.119 and promoter's grant no N501 217137. Authors express their gratitude to Ms.
Anna Krzymuska, a representative of Medicapteurs Co. in Poland for rendering available the Win-pod platform.

\section{References}

[1] J.W. Błaszczyk, Clinical Biomechanics, Wydawnictwo Lekarskie PZWL, Warszawa 2004, p. 192 (in Polish).

[2] J.W. Błaszczyk, P.D. Hansen, D.L Lowe, Acta Neurobiol. Exp. 53, 155 (1993).

[3] J.W. Błaszczyk, A. Piórko, D.H. Lowe, P.D. Hansen, Biocyber. Biomed. Eng. 14, 97 (1994).

[4] J. Olton, Posturograph. System, measurements and assessment of visual movable coordination. Users guide, Pro-Med., 2004, p. 1 (in Polish).

[5] J.W. Błaszczyk, W. Klonowski, Acta Neurobiol. Exp. 61, 105 (2001).

[6] S. Skrzyniarz, J. Kwaśniewski, Drivers Work Safety: Review of Directs Researches of Environment Impact on Driver Body in Car Transport, Wydawnictwo Instytutu Inżynierii Zarządzania Politechniki Poznańskiej, Poznań 2008, p. 187.

[7] B. Isaacs, Clinics in Geriatric Medicine 3, 277 (1985).

[8] J.W. Błaszczyk, L. Czerwosz, Gerontologia Polska 13 25 (2006) (in Polish).

[9] G. Dahlke, in: Conference Materials - Road Safety - Education and Diagnostics Steering Vehicles, Eds. W.M. Horst, G. Dahlke, Wydawnictwo Instytutu Inżynierii Zarządzania Politechniki Poznańskiej, Warszawa 2007, p. 73 (in Polish).

[10] Z. Damijan, Mol. Quant. Acoust. 29, 69 (2008). 